\title{
Life history patterns of the dorid nudibranchs Doridella steinbergae and Corambe pacifica
}

\author{
Paul M. Yoshioka \\ Department of Marine Sciences, University of Puerto Rico, Mayaguez, Puerto Rico 00708, USA
}

\begin{abstract}
Benthic life history traits of 2 ecologically similar nudibranchs, Doridella steinbergae and Corambe pacifica, were determined from laboratory rearing studies and examined in context with $\mathrm{r}$ and $\mathrm{K}$ selection. Although C. pacifica can produce a greater number of larvae, D. steinbergae has the higher maximum rate of natural increase, $r_{m}$, due to an earlier age at reproduction. Also, $D$. steinbergae is more efficient in the acquisition and utilization of their common prey resource. Thus, a trade-off in $r$ and $\mathrm{K}$ attributes does not exist between the 2 nudibranchs. A 'bet-hedging' interpretation, entailing a trade-off between reproductive output and probability of successful reproduction, provides a more suitable explanation of life history pattern. Bet-hedging occurs when sibling larvae settle on different kelp blades, thereby averaging out local variations in prey abundances.
\end{abstract}

\section{INTRODUCTION}

Central features of life history pattern can be summarized by 3 traits: (1) the total number of of fspring an organism produces; (2) its age at each reproduction; (3) its age at death (Mertz 1970). The scope of possible combinations of life history traits are evidently limited by trade-offs which prevent the evolution of species possessing only desirable characteristics, such as high fecundity, early reproduction, and long life (Law 1979). Specific details of costs and benefits associated with trade-offs generally involve the interaction of life history traits with physiological and populational consequences involved in the acquisition and utilization of resources. For instance, limited metabolic resources may allow rapid growth rates of individuals at a cost of delayed reproduction which, in turn, results in reduced population growth rates (e.g. Cole 1954).

Selective forces underlying trade-offs have often been attributed to specific ecological factors. Paine (1977) suggested that size-specific predation on smaller (younger) individuals favors the combination of rapid growth rates and delayed reproduction if individuals can thereby attain sizes exceeding the capacity of their predators. Murdoch (1966) demonstrated that increased mortality is associated with reproduction in the carabid beetle Agonum and postulated that enhanced adult survival resulting from delayed reproduction may enable populations to persist through periods unfavorable to the survival of other life stages. Other approaches have concentrated on more general patterns of survivorship. For instance, delayed reproduction decreases the rate of population decline and may be advantageous for species which traditionally experience long periods of unfavorable conditions (Mertz 1971). Also, delayed and iteroparous reproduction may be favored for marine fish species under conditions of highly variable juvenile survival (Murphy 1968).

Perhaps the best known theory of life history pattern is that of $r$ and K selection (MacArthur \& Wilson 1967. Pianka 1970, 1974). As derived from the logistic equation, $\mathrm{r}$ is defined as the intrinsic rate of natural increase and $\mathrm{K}$, the carrying capacity. Frequently, $\mathrm{K}$ is described in terms of superior competitive ability in the acquisition and utilization of limiting resources (e.g. MacArthur \& Wilson 1967). Also, K selection is characteristic of equilibrium conditions and $r$, of unsaturated environments (Pianka 1974). In essence, selection for $\mathrm{r}$ and $\mathrm{K}$ is mutually antagonistic and involves trade-offs between productivity ( $\mathrm{r}$ ) and efficiency of resource utilization (K) (MacArthur \& Wilson 1967).

A major difficulty of life history pattern studies is that alternative interpretations may not be mutually exclusive and predict similar results. For example, Murphy's (1968) model (termed 'bet-hedging' by Stearns 1976) demonstrates that variable juvenile mor- 
tality results in attributes associated with $\mathrm{K}$ selection, and variable adult mortality in the attributes of $r$ selection. Differences between alternative approaches are not trivial with respect to the underlying selective mechanisms. Murphy (1968) emphasized the variability of mortality, irrespective of the source, while $r$ and $K$ selection is based on the more restrictive premise that competition in terms of population growth rates (e.g. Cole 1954, Lewontin 1965) or efficiency (MacArthur \& Wilson 1967, Pianka 1974) represents the appropriate selective framework. Unfortunately, tests to distinguish between alternatives are usually lacking (Stearns 1977).

In this report I examine the life history patterns of 2 dorid nudibranchs, Doridella steinbergae Lance and Corambe pacifica MacFarland \& O'Donoghue. These nudibranchs are very similar in physical appearance and commonly co-occur in the Macrocystis pyrifera (L.) kelp canopy feeding on their only known prey, the bryozoan Membranipora membranacea (L.) (MacFarland \& O'Donoghue 1929, Lance 1962, McBeth 1968, Seed 1976, Yoshioka 1982a, Harvell 1984). M. membranacea population sizes may vary by more than an order of magnitude in $2 \mathrm{wk}$ and range from less than 1 to more than 1000 colonies per kelp blade seasonally (Yoshioka 1982b). These features suggest that prey resources span the spectrum from overabundance to severe limitation, thereby providing the requisites necessary for selection based on population growth rates ( $\mathrm{r}$ ) and competitive efficiency $(\mathrm{K})$.

I present laboratory rearing data of the benthic life stages of the nudibranchs and interpret the results in context of $r$ and $\mathrm{K}$ selection. Evaluation of $\mathrm{r}$ selection is based on a formal demographic definition of the maximum intrinsic rate of natural increase, $\mathrm{r}_{\mathrm{m}}$, and $\mathrm{K}$ selection on several measures of the efficiency of resource acquisition and utilization. I then test whether a tradeoff between $\mathrm{r}$ and $\mathrm{K}$ exists between Doridella steinbergae and Corambe pacifica. Finally, I compare the merits of $\mathrm{r}$ and $\mathrm{K}$ selection and bet-hedging in the ecology of the nudibranchs.

\section{METHODS}

Field-collected specimens of Doridella steinbergae and Coramba pacifica were reared in the laboratory at $13.5^{\circ} \mathrm{C}$. Freshly collected algal blades heavily encrusted with Membranipora membranacea were added in excess as food every 1 to $2 \mathrm{~d}$ when the seawater medium was changed. Because both nudibranchs are hermaphroditic cross fertilizers, conspecific pairs of larger and similar-sized individuals were kept in each test container. Also, because nudibranchs less than $0.2 \mathrm{~cm}$ could not be identified to the species level, a group rearing of newly settled veligers was used to estimate growth and feeding rates of smaller individuals.

Total body length and the number of zooids eaten and egg masses were laid were recorded when the food supply was changed. Both Doridella steinbergae and Corambe pacifica feed by rasping through the frontal membrane and sucking out the contents of Membranipora membranacea zooids (e.g. McBeth 1968). Feeding rates were thus based on counts of empty zooids before and after the addition of nudibranchs. Controls showed negligible loss of zooids over the time intervals involved. The number of eggs laid were based on subsample counts of egg masses. Laboratory experiments examining the relative efficiencies of the nudibranchs in the acquisition and utilization of zooids involved only pre-reproductive individuals. $D$. steinbergae ranged in size from 0.35 to $0.42 \mathrm{~cm}$ and C. pacifica from 0.60 to $0.73 \mathrm{~cm}$. Equal numbers of both species were placed in test containers with algal blades heavily encrusted with approximately 19200 M. membranacea zooids. Food was not changed in the course of the experiment. The number of nudibranchs placed in each container ranged from 4 (a pair of each species) to 32 (16 of each species).

\section{RESULTS}

Life history features of Doridella steinbergae and Corambe pacifica based on the rearing studies are given in Table 1. Several differences between the species are apparent. C. pacifica grows larger and displays higher size-specific and lifetime consumption rates of zooids. For instance, in the 0.2 to $0.42 \mathrm{~cm}$ size class C. pacifica consumes an average of 55 zooids per day compared to 27 for $D$. steinbergae. Reproduction begins about 17 and $26 \mathrm{~d}$ after settlement for $D$. steinbergae and $C$. pacifica, respectively. No differences were noted in the size and appearance of individual eggs (approximately $70 \mu \mathrm{m}$ in diameter) and newly hatched veligers (shell lengths: $130 \mu \mathrm{m}$ ) indicating no differential investment in energy per larva between the two species. Bickell \& Chia (1979) give similar measurements for $D$. steinbergae. Although the total number of egg masses laid by the 2 species are not statistically different (10 for C. pacifica versus 10.5 for D. pacifica), lifetime reproduction by $C$. pacifica is higher because of the larger number of eggs per egg mass, $2550 \pm 596(95 \%$ C.I., $\mathrm{n}=8$ ) compared to 1135 $\pm 250(\mathrm{n}=7)$ for $D$. steinbergae.

In the laboratory no mortality was observed prior to reproduction and all individuals succumbed after reproductive periods of about $8 \mathrm{~d}$ for Doridella steinbergae and $17 \mathrm{~d}$ for Corambe pacifica. A notable fea- 
Table 1. Doridella steinbergae and Corambe pacifica. Reproduction, zooid consumption, and duration of various size classes. $\mathrm{n}=$ \# pairs of $D$. steinbergae and C. pacifica each. ' group rearing of 4 Doridella and 5 Corambe; $\cdots$ maximum sizes of $D$. steinbergae and C. pacifica. $95 \% \mathrm{CI}$ based on pairs. Probabilities based on the t-test. NS = not significant at 0.05 level

\begin{tabular}{|c|c|c|c|c|c|c|c|c|c|c|}
\hline \multirow[t]{2}{*}{$\begin{array}{l}\text { Size class } \\
\quad(\mathrm{cm})\end{array}$} & \multirow[t]{2}{*}{$\mathrm{n}$} & \multicolumn{2}{|c|}{$\begin{array}{l}\text { Duration } \\
\text { (d) }\end{array}$} & \multirow[t]{2}{*}{$\mathrm{p}$} & \multicolumn{2}{|c|}{ \# Zooids consumed } & \multirow[t]{2}{*}{$\mathrm{p}$} & \multicolumn{2}{|c|}{ \# Egg masses laid } & \multirow[t]{2}{*}{$\mathrm{p}$} \\
\hline & & Doridella & Corambe & & Doridella & Corambe & & Doridella & Corambe & \\
\hline$<0.2$ & $9^{\circ}$ & $10.7 \pm 1.6$ & $10.7 \pm 1.6$ & - & $54.3 \pm 11.4$ & $54.3 \pm 11.4$ & - & 0 & 0 & - \\
\hline $0.2-0.42$ & 8 & $5.9 \pm 1.5$ & $7.4 \pm 3.2$ & NS & $160.5 \pm 48.4$ & $405.0 \pm 234$ & 0.05 & 0 & 0 & - \\
\hline $0.42-0.82 \cdots$ & 8 & $7.8 \pm 0.7$ & & & $614.5 \pm 49.7$ & & - & $10.5 \pm 2.3$ & & \\
\hline $0.42-0.73$ & 8 & & $7.5 \pm 2.7$ & & & $1513.1 \pm 941$ & - & & 0 & \\
\hline $0.73-1.3 \cdots$ & 8 & & $17.3 \pm 6.4$ & & & $8545.0 \pm 770$ & & & $9.7 \pm 3.0$ & \\
\hline Lifetime totals & & 24.4 & 42.9 & & 829.3 & 10517.9 & & 10.5 & 9.7 & NS \\
\hline
\end{tabular}

ture observed during the rearing study was low variability in the size (age) of first reproduction; without exception $D$. steinbergae and $C$. pacifica began reproduction upon reaching threshold sizes of 0.42 and 0.73 $\mathrm{cm}$, respectively.

Age-specific reproductive rates of Doridella steinbergae and Corambe pacifica can be used to calculate the maximum intrinsic rate of natural increase, $r_{m}$. defined by the Lotka-Euler equation:

$$
1.0=\Sigma l_{x} m_{x} e^{-x}
$$

where $\mathrm{l}_{\mathrm{x}}=$ age-specific survivorship which I assumed to be 1.0 until reproduction ceases. Age-specific birth rate, $m_{x}$, would be expressed by the number of eggs laid per day. For simplicity and lack of evidence to the contrary, I assumed that reproduction proceeds at a constant rate for mature individuals with $D$. steinbergae and C. pacifica producing 1528 and 1430 eggs per day, respectively. Individual age, $\mathrm{x}$, would include time spent as eggs and veligers in addition to the post settlement times measured in the laboratory. Egg masses of both nudibranchs take 6 to $7 \mathrm{~d}$ to hatch (Yoshioka 1973). D. steinbergae veligers spend a minimum of 25 to $26 \mathrm{~d}$ in the plankton (Bickell et al. 1981). I also assumed this value for C. pacifica, based on the similar egg and veliger sizes of both species. Thus, C. pacifica and D. steinbergae would be a minimum of 57 and $48 \mathrm{~d}$ old, respectively, when reproduction begins.

Despite its lower fecundity, Doridella steinbergae has a higher $r_{m}$ than Corambe pacifica, 0.181 compared to $0.159 \mathrm{~d}^{-1}$, respectively.

A major difficulty of $r$ and $K$ selection is that $K$ cannot be expressed in terms of life history phenomena, and as a result $\mathrm{r}$ and $\mathrm{K}$ attributes cannot be compared directly (Stearns 1977). I attempted to measure $\mathrm{K}$ attributes of the nudibranchs by assuming that (1) Membranipora membranacea zooids represent the appropriate limiting resource and (2) reproductive output is the best measure of individual success during the benthic life stage. With these criteria, reproductive output would be dependent upon the efficiency at which zooids are acquired and utilized. In terms of resource utilization, Doridella steinbergae is the more efficient species in egg production in relative to zooid consumption whether these ratios are determined over the entire benthic lifespan or limited to the reproductive period. For instance, averaged over the entire lifespan, D. steinbergae produces 14.6 eggs per zooid consumed compared to 2.4 for C. pacifica.

The ability to acquire Membranipora membranacea zooids is potentially affected by behavioral interactions between individuals as well as the ability to locate dispersed prey. The former consideration evidently does not play an important role since no interor intraspecific interactions (exclusive of copulation) were observed in the laboratory, indicating that competition for limited resources would occur by exploitation rather than interference mechanisms. Thus, the successful acquisition of zooid resources would probably be related simply to the ability to locate zooids. In this respect the most striking behavioral difference observed between the nudibranchs was the constant activity of Doridella steinbergae compared to Corambe pacifica. This feature is reflected by characteristic feeding patterns of the nudibranchs; zooids eaten by $D$. steinbergae are dispersed haphazardly within $M$. membranacea colonies (McBeth 1968), while $C$. pacifica leaves large contiguous patches of empty zooids (MacFarland \& O'Donoghue 1929).

The preceding comparisons indicate that Doridella steinbergae would reproduce more successfully under conditions of limited zooid resources. To verify this conclusion, I put various desities of both species in containers with similar-sized sections of algal blades encrusted with Membranipora membranacea. Prey density per nudibranch ranged from sufficient to severely limiting based on the lifetime requirements of both species. In general, reproduction per individual for both species decreased with increasing nudibranch 
Table 2. Doridella steinbergae (D. s.) and Corambe pacifica (C. p.). Number of egg masses laid per individual during competition experiment; totals and ratios

\begin{tabular}{|c|c|c|c|c|c|c|}
\hline \multirow{3}{*}{$\begin{array}{l}\text { Number of } \\
\text { Nudibranchs } \\
\text { D. s.: C. p. }\end{array}$} & \multicolumn{4}{|c|}{ Days } & \multirow{2}{*}{ Total } & \multirow{2}{*}{ Ratio } \\
\hline & $0-1$ & $1-4$ & $4-10$ & $10-18$ & & \\
\hline & D. s.: C. p. & D. s.: C. p. & D. s.: C. p. & D. s.C. p. & D. s. C. p. & D. s. C. p. \\
\hline $2: 2$ & $2.0: 2.0$ & $1.5: 1.5$ & $2.5: 3.0$ & $0.0: 1.0$ & $6.0: 7.5$ & 0.80 \\
\hline $4: 4$ & $1.5: 0.8$ & $1.8: 1.0$ & $3.0: 2.0$ & $2.0: 0.0$ & $8.3: 3.8$ & 2.20 \\
\hline $8: 8$ & $0.9: 0.3$ & $1.4: 0.5$ & $1.6: 0.8$ & $1.1: 0.1$ & $5.0: 1.6$ & 3.08 \\
\hline $16: 16$ & $1.6: 0.3$ & $1.9: 0.4$ & $0.9: 0.4$ & $0.0: 0.1$ & $4.4: 1.1$ & 3.94 \\
\hline
\end{tabular}

density indicating the effects of resource limitation (Table 2). More importantly, D. steinbergae laid a comparatively greater number of egg masses than Corambe pacifica with increasing nudibranch density $(p=0.04,1$-tailed, exact probability test) confirming the prediction of greater reproductive success under conditions of resource limitation.

\section{DISCUSSION}

The theory of $\mathrm{r}$ and $\mathrm{K}$ selection may appear appropriate for Doridella steinbergae and Corambe pacifica because both species possess a suite of life history traits and ecological correlates characteristic of $r$ selection (Pianka 1974). These include: (1) rapid growth, (2) early reproduction, (3) many small offspring, (4) small body size, (5) short lifespan, (6) occurrence in an uncertain environment (Yoshioka 1982b), (7) variable and nonequilibrium population sizes (Yoshioka unpubl.), (8) frequent recolonizations (Yoshioka 1982a). However, counter to theoretical expectation, D. steinbergae has a higher $r_{m}$ and is more efficient in the acquisition and utilization of prey resources, and consequently a trade-off does not exist between population growth rates $(r)$ and efficiency $(K)$. The higher $\mathrm{r}_{\mathrm{m}}$ of $D$. steinbergae, despite lower fecundity, is attributable to the overwhelming role of the age of first reproduction in determining population growth rate (Cole 1954, Lewontin 1965). Also, because the greater fecundity of C. pacifica probably results from its greater size which, in turn, requires longer development times, $r$ and $K$ selection cannot explain the trade-off between fecundity and development time. Furthermore, $r$ and $\mathrm{K}$ may be even positively correlated in these nudibranchs. Egg production relative to zooid consumption (efficiency) probably increases with shorter developmental periods because proportionately more metabolic energy may be required for non-reproductive metabolic processes (as maintenance) with longer developmental periods.

A major consequence of these considerations is that $r$ and $\mathrm{K}$ selection cannot account for the coexistence of the nudibranchs. Doridella steinbergae would have a higher population growth rate if prey resources are always overabundant and would produce proportionally more offspring if resources were always limiting. Since $D$. steinbergae is the superior species at both extremes of resource availability, the exclusion of Corambe pacifica would appear imminent.

An alternative interpretation of the life history patterns of the nudibranchs can be formulated from the perspective of coexistence: (1) How can differences in life history pattern account for their coexistence? (2) What are the selective forces and trade-offs implied thereby? An essential ingredient of coexistence is the interaction between the complex life cycles of the nudibranchs and the dynamics of their prey. Membranipora membranacea populations exhibit large short-term (biweekly) fluctuations in size with densities sufficient to support the successful growth and reproduction of the nudibranchs occurring at episodic intervals (Yoshioka 1982b). Doridella steinbergae and Corambe pacifica have adapted to these conditions by settling only in instances of high prey densities, suggesting that veligers can delay settlement and wait in the plankton for proper settling conditions (Yoshioka 1982a, unpubl.). The resulting implication of a planktonic 'seed bank' (Harper 1977) is supported by field experiments. Large numbers of both nudibranchs can be induced to settle out if heavily encrusted algal blades are placed in the field, even during periods when both species are absent in kelp beds due to low $M$. membranacea abundances (Yoshioka 1982a). In concordance, Bickell et al. (1981) have demonstrated that the settlement of $D$. steinbergae can be delayed for $25 \mathrm{~d}$ past the attainment of metamorphic competence.

The preceding observations indicate that early reproduction in the benthic life stage of Doridella steinbergae is offset by a corresponding increase in time spent in the plankton awaiting proper settling conditions. As a result, the effective generation times of the nudibranchs would be equivalent and determined by temporal features of the prey population rather than endogenous developmental rates. The net effect can be simply demonstrated by the relation: 


$$
r=\ln R_{0} / T
$$

where $R_{0}=$ net reproductive potential; $T=$ environmentally determined generation time which would be equivalent for both species in a given situation. Given equivalent generation times, coexistence would be dependent upon an environmental regime in which the relative advantages of both $D$. steinbergae (reproductive efficiency) and Corambe pacifica (fecundity) can be expressed. This is evidently the case. Variations in the relative abundance of prey range from less than 50 to more than 100000 zooids per nudibranch on individual kelp blades at a given time (Yoshioka unpubl.). Based on the rearing data, these values span the spectrum from no, to partial, to complete reproduction by the nudibranchs. Consequently, reproduction $\left(\mathrm{R}_{0}\right)$ of either $D$. steinbergae or C. pacifica would be greater depending upon the relative abundance of prey. It should be noted that, counter to a simplifying assumption, C. pacifica would have the shorter larval developmental period under these conditions. However, I selection based on innate developmental processes would still represent the inappropriate mechanism. Schaal \& Leverich (1981) give a similar argument for annual plants where the age of reproduction has little effect on $r$ because of exogenous (seasonal) factors.

This scenario of coexistence is readily amenable to a 'bet-hedging' interpretation of life history pattern. Bethedging would occur in the larval life phase when planktonic dispersal results in sibling veligers settling on different kelp blades, thereby 'averaging out' spatial variations in reproductive success. Variations in the germination of desert plant seeds within a given seed set (Cohen 1966) represents a similar example of pre-reproductive bet-hedging set in a temporal context. Bet-hedging provides a satisfactory explanation for the trade-off between fecundity and development time as well as the low variability observed in the age (size) of first reproduction. I have demonstrated elsewhere (Yoshioka unpubl.) that the availability of food on kelp blades becomes more uncertain with time (nudibranch age). Thus, the larger reproductive output of Corambe pacifica associated with its longer developmental period would be incurred at a cost of increased variability in reproductive success. Similarly, if low variability is indicative of high selective pressure (Lewontin 1965), then it can be inferred that the benthic life stage is under strong selective pressure to reproduce as quickly as possible (within the life history framework of the nudibranchs) in order to reduce variations in reproductive success. (In contrast, the ineffectiveness of early reproduction in determining population growth rates invalidates $r$ selection as the appropriate mechanism.)

Physiological constraints may ultimately underlie the trade-off between fecundity and the age of reproduction. Doridella could easily match the reproductive outout of Corambe by reproducing over a longer time span. In other words, the ideal strategy appears to be reproduction as early and as long as possible. The death of all nudibranchs after a short period of reproduction (typifying the classical Type I survivorship curve) indicates the presence of physiological tradeoffs between fecundity and development time which preclude this possibility.

Acknowledgements. G. Breckon, D. Harvell, G. Owen, R. Strathmann, and an anonymous reviewer read and improved previous drafts of this manuscript. Partial support during the preparation of this manuscript was provided by the Marine Ecology Division of the Center for Energy and Environment Research, Mayaquez, Puerto Rico.

\section{LITERATURE CITED}

Bickell, L. R., Chia, F. S. (1979). Organogenesis and histogenesis in the planktotrophic veliger of Doridella steinbergae (Opistobranchia: Nudibranchia). Mar. Biol. 52: $291-313$

Bickell, L. R., Chia, F. S., Crawford, B. J. (1981). Morphogenesis of the digestive system during metamorphosis of the nudibranch Doridella steinbergae (Gastropoda): Conversion from phytoplanktivore to carnivore. Mar. Biol. 62: $1-16$

Cole, L. C. (1954). The population consequences of life history phenomena. Q. Rev. Biol. 29: 103-137

Cohen, D. (1966). Optimizing reproduction in a randomly varying environment. J. theor. Biol. 12: 119-129

Harper, J. L. (1977). Population biology of plants. Academic Press, London

Harvell, C. D. (1984). Predator-induced defense in a marine bryozoan. Science 224: 2357-1359

Lance, J. R. (1962). A new Stiliger and a new Corambella (Mollusca: Opistobranchia) from the N.W. Pacific. Veliger 5: 33-38

Law, R. (1979). Ecological determinants in the evolution of life histories. In: Anderson, R. M., Turner, B. D., Taylor, L. R. (ed.) Population dynamics. Blackwell, London, p. $81-103$

Lewontin, R. C. (1965). Selection for colonizing ability. In: Baker, H. G., Stebbins, G. K. (ed.) The genetics of colonizing species. Academic Press, New York, p. 79-94

MacAsthur, R. H., Wilson, E. O. (1967). The theory of island biogeography. Princeton Univ. Press, Princeton

MacFarland, F. M., O'Donoghue, C. H. (1929). A new species of Corambe from the Pacific Coast of North America. Proc. Calif. Acad. Sci., ser. 4. 18: 1-27

McBeth, J. W. (1968). Feeding behavior of Corambella steinbergae. Veliger 11: 145-146

Mertz, D. B. (1970). Life-histories and ecological genetics. In: Connell, J. H., Mertz, D. B., Murdoch, W. W. (ed.) Ecology and ecological genetics. Harger and Row, New York, p. $1-3$

Mertz, D. B. (1971). Life history phenomena in increasing and decreasing populations. In: Patil, G. P., Pielou, E. C., Waters, W. E. (ed.) Statistical ecology, Vol. 2. Penn. State Univ. Press, University Park, p. 361-399

Murdoch, W. W. (1966). Population stability and life history phenomena. Am. Nat. 100: 45-51 
Murphy, G. I. (1968). Pattern in life history and the environment. Am. Nat. 102: 390-404

Paine, R. T. (1977). Controlled manipulations in the marine intertidal zone and their contributions to ecological theory. In: Goulden, C. E. (ed.) The changing scenes in the natural sciences, 1776-1976. Fulton Press, Lancaster, p. $245-270$

Pianka, E. R. (1970). On $\mathrm{r}$ and $\mathrm{K}$ selection. Am. Nat. 104: 592-597

Pianka, E. R. (1974). Evolutionary ecology. Harper and Row, New York

Schaal, B. A., Leverich, W. J. (1981\}. The demographic consequences of two-stage life cycles: survivorship and the time of reproduction. Am. Nat. 118: 135-138

Seed, R. (1976). Observations on the ecology of Membranipora (Bryozoa) and a major predator Doridella steinbergae (Nudibranchiata) along the fronds of Laminaria sac- charina at Friday Harbor, Washington. J. exp. mar. Biol. Ecol. 24: 1-17

Stearns, S. C. (1976). Life history tactics: a review of the ideas. Q. Rev. Biol. 51. 3-47

Stearns, S. C. (1977). The evolution of life history tactics: a critique of the theory and a review of the data. A. Rev. Ecol. Syst. 8: 145-171

Yoshioka, P. M. (1973). The population dynamics and ecology of the encrusting ectoproct Membranipora serrilamella. Dissertation. Univ. Calif., San Diego

Yoshioka, P. M. (1982a). Predator-induced polymorphism in the bryozoan Membranipora membranacea (L.). J. exp. mar. Biol. Ecol. 61: 233-242

Yoshioka, P. M. (1982b). Role of planktonic and benthic factors in the population dynamics of the bryozoan Membranipora membranacea. Ecology 63: 457-468

This article was presented by Professor J. S. Pearse; it was accepted for printing on April 14, 1986 